\title{
Khat use and related addiction, mental health and physical disorders: the need to address a growing risk
}

\author{
Michael Odenwald ${ }^{1,2}$ and Mustafa al'Absi ${ }^{3}$
}

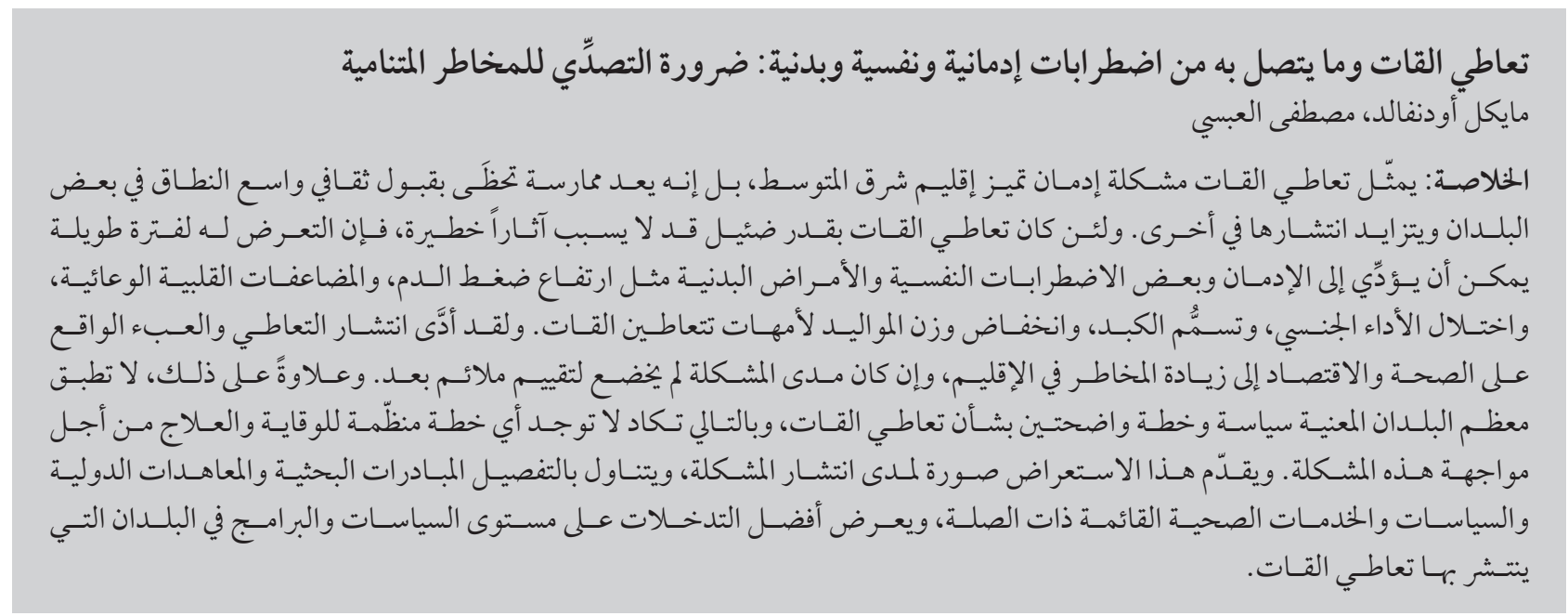

ABSTRACT Khat use is a drug problem characteristic of the Eastern Mediterranean Region, which is a widespread culturally accepted practice in some countries and is becoming more prevalent in others. Although limited use may not be accompanied by serious consequences, prolonged exposure could lead to dependence, psychosis and other psychiatric disorders and physical conditions such as hypertension, cardiovascular complications, sexual dysfunction, hepatoxicity and reduced birth weight of infants born to khat-chewing mothers. The widespread use and its burden on health and economy has raised concerns in the Region, although the extent of the problem is not well assessed. Additionally, most countries do not have a clear policy and plan with regard to khat use, and therefore there is hardly any structured prevention and treatment plan in place to respond to the problem. This review presents a picture of the extent of the problem, elaborates on related existing research initiatives and international treaties, policies and health service provisions, and outlines best policy and programme interventions in khat-use countries.

Consommation de khat, dépendance, affections de santé mentale et troubles physiques associés : nécessité de s'attaquer à un risque croissant

RÉSUMÉ La consommation de khat est un problème de toxicomanie caractéristique de la Région de la Méditerranée orientale. Elle constitue une pratique largement acceptée au plan culturel dans certains pays et devient de plus en plus prévalente dans d'autres. Bien qu'une consommation limitée ne s'accompagne pas de conséquences graves, une exposition prolongée peut conduire à la dépendance, à la psychose et à d'autres troubles psychiatriques, ainsi qu'à des états pathologiques physiques telles que l'hypertension, des complications cardio-vasculaires, un dysfonctionnement sexuel, une hépatotoxicité et une réduction du poids à la naissance pour les enfants nés de mères consommatrices de khat. L'utilisation répandue du khat et la charge qu'elle exerce sur la santé et l'économie suscitent des inquiétudes dans la Région, bien que l'étendue du problème ne soit pas parfaitement estimée. En outre, la plupart des pays ne disposent pas de politiques et de plans clairs concernant la consommation de khat. II n'y a donc pour ainsi dire quasiment aucun plan de prévention et de traitement structuré en place pour répondre à ce problème. La présente analyse donne un aperçu de l'étendue du problème, détaille les initiatives de recherche et les traités internationaux existants sur la question, les politiques et les prestations de services, et définit les meilleurs politiques et programmes d'intervention dans les pays où la consommation de khat existe.

'Department of Psychology, University of Konstanz, Konstanz, Germany; ${ }^{2}$ Vivo International, Germany (Correspondence to: M. Odenwald: michael. odenwald@uni-konstanz.de). ${ }^{3}$ Khat Research Program (KRP), University of Minnesota Medical School, Duluth, United States of America.

Received: 19/05/16; accepted: 24/11/16 


\section{Background}

A unique characteristic of drug use in the Eastern Mediterranean and North African region is the culturally sanctioned use of khat. Khat use is widely prevalent in countries like Yemen, Kenya, Somalia, Ethiopia and Djibouti and an increasing pattern is reported from some other countries such as Oman and Saudi Arabia $(1,2)$. There are also studies showing a growing problem of khat use in the United Kingdom (UK) and European countries, specifically among the migrant communities (3). The exact number of khat users is unclear but it is estimated that more than 10 million people use khat on any day (1), predominantly in the mentioned countries, with a male predominant pattern. Yemen, where khat use is culturally accepted, has the largest population of khat users. It had been reported that 15 to $20 \%$ of children under 12 years of age use khat (lifetime) in Yemen (4). Today, the domestic khat market greatly contributes to Yemen's national economy and Ethiopia and Kenya earn a significant proportion of their foreign currencies by khat exportation (5).

Khat comes from the young and tender leaves and shoots of the khat tree (Catha edulis). Khat leaves have been consumed for centuries for their mildly stimulating properties caused by several alkaloids. Cathinone [S-(-)-alpha-aminopropiophenone] is considered to be the main psychoactive compound, but it is unstable and swiftly decomposes after harvesting; cathinone resembles amphetamine in chemical structure and affects the central and peripheral nervous system and behaviour similarly (6).

While chewing the fresh leaves has always been preferred, in the past it was often only available in dried form, powder or paste, e.g. to brew as "Abyssinian tea” or "Bushman's tea” (7). Today, soon after harvesting, the twigs and shoots are rolled into bundles and wrapped in banana leaves in order to retain moisture (8). In most instances, bundles are the traded units, but lower qualities might also be marketed in standard plastic bags (9). The leaves and tender stems are usually chewed and kept in a tight wad in the cheek. Within about 30- 60 minutes the user experiences excitability, euphoria, talkativeness and flow of ideas, known among khat users in a number of countries as mirquaan (10). This is followed by a quieter, more introvert phase, giving way to a gradual comedown, and often restlessness, irritability and a depressive reaction (11). These unpleasant aftereffects motivate khat chewers to carry on chewing without stopping (5). Users often experience sleep problems during the night and a hangover the next morning (1). Usually, regular khat users experience psychological withdrawal symptoms at the time of the day of their usual khat intake (in Somali known as haddar) which involves restlessness, concentration difficulties, irritability and impaired impulse control (1).

Since the mid-20th century, khat use patterns have profoundly changed and become more excessive and informal - i.e. not restricted to traditional and formal use occasions and by the traditional use norms $(2,12)$. This is related to the increased availability and spread of the habit to groups that have traditionally not had contact with the substance (1). While khat users traditionally were mono-substance users, more recently concomitant use is increasingly reported, indicating that khat users functionally modulate their physiological and psychological state with a set of other substances $(13,14)$. Most obvious is tobacco use which is strongly associated with khat use (15). Research efforts in Yemen have documented that the vast majority of khat users also smoke tobacco but the casual direction or origin of this khat- tobacco use association is unknown $(15,16)$. Data from Yemeni khat users with and without nicotine use in the UK have led researchers to hypothesize on an enhancement effect (17).
Khat use has been associated with numerous health problems. Basic research studies have found evidence of altered stress response (18), cognitive deficits $(19,20)$ and insomnia (21) in habitual khat users. Research has shown that prolonged exposure to khat may lead to a long-lasting sensitization to the effects of other drugs (22). In addition to physical and mental harm, much time and household income is spent in obtaining and chewing khat (23), which severely affects the users' social life and family (24).

\section{Adverse effects of khat use}

\section{Dependence}

Excessive and prolonged khat use could have the potential to induce psychological dependence with a dominant feature similar to dependence on amphetamine-type stimulants, although more empirical studies are needed in this regard (1). The potential to induce psychological dependence is confirmed by a number of recent studies, using a version of the Severity of Dependence Scale (SDS) that has been adapted and validated for the study of khat dependence $(25,26)$. It has been shown that khat chewers scoring high on this instrument show more khat-related behaviours and have higher khat alkaloid levels in their saliva (27). About 39\% of a sample of Yemeni khat users living in the UK scored at a level comparable with a clinical population with severe heroin dependence in need of treatment (28).

Little information is available on the prevalence of khat dependence as defined by the International Classification of Diseases (ICD) or Diagnostic and Statistical Manual of Mental Disorders (DSM). Recently, a study showed the applicability of the dependence syndrome as defined by DSM-IV (29): $31 \%$ of a group of 204 khat users of Yemeni origin living in the UK fulfilled the 
DSM-IV criteria for dependence (29) while $84 \%$ of 25 chronic psychotic patients in Somalia (30) and 100\% among 33 khat-using male Somali refugees in Nairobi (9) fulfilled the DSM-IV criteria for dependence. An early Ethiopian study, using the WHO's Composite International Diagnostic Interview, found a lifetime prevalence of khat dependence according to the ICD-10 criteria of $5 \%$ among males (1.3\% among females) in a representative sample from a traditional khat-producing area (31). More recent population-based studies on khat dependence are missing in any of the khat-using countries.

\section{Psychosis and other psychiatric disorders}

Khat use is higher among individuals suffering from traumatic and stressful events $(9,32)$, those with pre-existing mental disorders (33) in an attempt to "self-medicate" pre-existing symptoms such as depression, anxiety and trauma (34,35), and those experiencing medication side-effects (36). Khat helps individuals with mental disorders to feel better but increases the risk of additional psychotic symptoms (34). More than 20 case reports describe khat-induced psychotic disorders (1,37). Systematic information on family vulnerability to psychosis is not reported, although in one case with a family history, a small amount seemed to be sufficient for the psychotic reaction. Some other clear features emerged: most cases had used khat excessively before the onset of psychotic symptoms and showed violent behaviour in the course of the disorder. Most cases completely remitted upon abstinence within 2-4 weeks even without medication. But most cases had repeated such episodes. Some recent studies confirmed the effects of khat use on pre-existing psychotic disorders $(30,36,38,39)$. However, the effects of khat use on psychotic exacerbation depend on the specific khat-chewing patterns (noxious patterns are: high quantity use, daily use, nighttime use, very long use sessions), the amount used and whether a patient discontinues the antipsychotic medication or not $(30,36)$.

A few studies have started to address the question of whether khat use might be a risk factor for the development of chronic psychotic disorders $(14,39,40)$. Early onset of use and excessive consumption were suggested as potential risk factors, but the evidence is preliminary.

Taken together, the recent findings partly support earlier reports on the harm of khat use to mental health, specifically with excessive use and among vulnerable individuals (e.g. those with pre-existing mental disorders and a high trauma and stress load as well as adolescent users). Moderate khat use does not appear to cause mental disorders perse (41).

\section{Physical disorders}

Besides psychiatric sequelae, numerous physical health problems have been associated with khat use $(42,43)$. A comprehensive review of the physical effects of khat use is beyond the scope of this paper as we focus here on mental health consequences. As with mental health, adverse effects are commonly linked with prolonged or excessive use. However, the major shortcoming of this literature is that other explanations for the physical disorders have not been systematically ruled out, for example tobacco smoking which is frequently combined with khat use $(15,21)$ and the agrochemical content in the leaves $(44,45)$. The negative physical consequences associated with khat use include mucosal problems (46), oral lesions (47), gastric cancers and duodenal ulcers (42), hypertension (48), cardiovascular complications (49), stroke (50), sexual dysfunction (51), hepatoxicity (52) and reduced birth weight of infants born to khat-chewing mothers (53), to mention just a few.
Additional recent findings in the literature relevant to the effect of chronic khat use are indicated in Box 1.

\section{Current international research initiatives}

Several international initiatives currently exist in the field of khat research.

1. The NIH-funded international Khat Research Program is the largest current research initiative with a high scientific output. The programme was initially launched as part of a Fogarty International Research Collaboration Award (FIRCA) from the $\mathrm{NIH}$ in 2005 .

Ongoing research coordinated by the Khat Research Program seeks to develop a knowledge base to guide the development of effective harm reduction, prevention and treatment strategies for concurrent tobacco-khat use. The Program to date has particularly focused on mapping the effects of khat use and identifying potential targets that may be addressed in future prevention and intervention efforts. There is virtually no empirical information to inform effective intervention techniques to reduce or discontinue khat use in either khat-only users or concurrent khat and tobacco users, but the Program's collective knowledge output could provide a solid basis for development of evidence-based interventions that are feasible, cost-effective and scalable in low-resource settings. This would fill a clear gap in efforts to reduce any harm to public health that may be caused by khat use. Additionally, the increased use among women and children, the concurrent use of tobacco and the potential increase in abuse of other drugs (e.g., abuse of sedatives) adds urgency to this effort (62).

2. In Saudi Arabia, the Substance Abuse Research Center (SARC, http:// sarc.sa/portal/home.html) was established in 2011 by the University of Jazan with a focus on the substance 


\section{Box 1. Recent findings on the effects of chewing khat}

\section{Animal research verifies:}

- Dose-dependent effect of cathinone on aggression, anxiety, withdrawal and appetite using vervet monkeys (54)

- Dose- and time-dependent effect of cathinone on stress and sex hormone production (55)

\section{Chronic khat use leads to:}

- Impaired attention and working memory (19,56-58)

- Higher experience of anger and more pronounced negative reactions during stress (59)

- Abnormal diurnal stress hormone profile: enhanced evening and attenuated morning cortisol levels (18)

\section{Concurrent tobacco use among khat chewers is:}

- Greater in males (16)

- Culturally proscribed: males use cigarettes, while females use shisha $(16,60)$

- Harmful to short-term memory, learning and delayed recall $(20,58)$

- Linked to abnormal (blunted) cardiovascular response to stress (61)

use patterns in Jazan province where khat use has been a traditional practice and current use patterns are becoming more excessive. Its aim is carry out research and support educational campaigns and provision of treatment in the community. SARC has conducted a series of epidemiological studies to shed light on the current khat use and its associated problems in Jazan province (e.g. school performance and quality of life) (63-66). It has also conducted studies to gain insight into motives for using khat and to explore reasons for and subjective consequences of quitting among a group of volunteers who had stopped khat use $(67,68)$. The study provides insight into how khat chewers can be supported to stop using it. The centre is currently planning a longitudinal study to compare the benefits of bupropion versus placebo administration on discontinuation of khat use and abstinence.

3. An initiative funded by the German government, which currently involves the University of Konstanz (Germany), the University of Nairobi (Kenya), the University of Munich (LMU, Germany), the University of Jimma
(Ethiopia) and several NGOs, aims i) to develop and evaluate sustainable interventions for community-based mental health care that include khat $(30,69,70)$, ii) to develop and evaluate currently not available research and clinical methods $(30,71)$ and iii) to study the effects of khat use on psychotic developments in crosssectional and longitudinal studies in order to identify noxious khat use patterns and mediating and moderating variables (9).

\section{International drug control treaties: key provisions for khat and its metabolites}

The following khat alkaloids are internationally controlled: cathinone is listed in Schedule I and cathine in Schedule III of the International Convention on Psychotropic Substances of 1971 and norephedrine is controlled under the 1988 Convention against Illicit Traffic in Narcotic Drugs and Psychotropic Substances (72).
In contrast to that, khat leaves are currently not scheduled or controlled under international conventions. The WHO Expert Committee on Drug Dependence critically reviewed khat in its 34th session in 2006 (72). They concluded that evidence was not enough to warrant international control of khat leaves and did not recommend scheduling them. However, in view of the potential adverse health consequences of excessive khat use patterns, they recommended that member countries should adopt educational campaigns in order to inform the public about the potential negative consequences and discourage its use. This is supported by scientific reviews, i.e. compared to other substances of abuse, khat leaves have a low potential for dependence, and physical and social harm $(73,74)$.

In the WHO Eastern Mediterranean Region, most khat countries currently have a laissez-faire attitude concerning khat (Yemen, Somalia, Djibouti) while Saudi Arabia has banned it. In its 6th meeting in 2007, the Regional Advisory Panel on Impacts of Drug Abuse (RAPID) of the WHO Regional Office for the Eastern Mediterranean 
conducted an intercountry consultation on khat (75). The panel discussion highlighted that khat is a sensitive issue in the Region, that a balanced approach is required and that in-depth studies on the scope of the problem are currently missing to guide politics. The panel developed 7 recommendations for the Member States that especially addressed the potentially harmful nontraditional excessive use patterns: 1 ) Contain the use of khat though marketinterventions similar to tobacco, 2) Conduct awareness-raising activities on the health and social consequences, 3) Protect vulnerable groups such as children, women and people with preexisting mental disorders, 4) Make international research literature available, 5) Establish and maintain appropriate surveillance systems, 6) Generate evidence through research to guide informed policies and interventions, and 7) Undertake a coordinated interagency, inter- and intragovernmental and nongovernmental organization effort to address the multisectoral and interdisciplinary activities related to khat.

In the European Union, where millions of immigrants from khat countries reside, the khat trade has been growing for more than a decade and legitimate and illegal transportation networks have emerged. Among the European Community countries, 15 members and Norway have imposed a ban on khat leaves so far (most recently The Netherlands in 2013 and Great Britain in 2014); in the rest, the status of khat leaves is not specifically controlled under drug laws (3). In 2011, the European Monitoring Centre for Drugs and Drug Addiction published a policy briefing on khat (76). In the briefing, the weak data sources are pointed out and a balanced and multisectoral approach is recommended focusing on the potential harms.

In the United States of America, the import and trafficking of khat leaves are controlled by the Drug Enforcement
Agency because khat alkaloids are scheduled substances under the Controlled Substance Act (cathinone Schedule I, cathine Schedule IV).

\section{Review of interventions}

In general, there is a scarcity of research on psychological and pharmacological interventions that address khat-related health problems. The developments, mainly related to khat dependence and mental health problems among khat chewers, are reviewed briefly:

Webpages, non-scientific reports and observations reported in scientific papers, as reviewed by Odenwald and colleagues (77), reveal that several forms of khat counselling and dependence treatment currently exist, offered by different service providers. In several European countries, public treatment services for individuals with khat dependence are offered by integrating them into the existing services for illegal substances. Several projects have been implemented to assist dependent khat users to access and utilize such services. Although no scientific evaluation has been conducted, at least there are descriptions of methods used and experiences in single publications and reports. For example, several reports describe an outreach project in Aarhus, Denmark for khat-addicted individuals among the Somali immigrant community $(78,79)$. Somali community workers identify khat addicts, assist them with their every-day problems and accompany them on their way through out- and inpatient substance use treatment and psychiatric services. Of about 100 clients in the project period, 27 were brought in for substance use treatment and 19 suffered from additional mental disorders. Similar projects have been implemented in the UK, e.g. by the nongovernmental charity organization MIND.

Very few substance use treatment services offer specialized khat treatment. In Sweden, the Stockholm County
Council substance treatment services opened a specialized outpatient clinic for khat use disorders in 2012, especially targeting the migrant population from countries with a high prevalence of khat use (80). In 2013, a year after opening, about 10 people had approached the clinic, most of them with external motivation (sent by the social services department) (Abdi YA, personal communication, 2013).

Very few psychotherapeutic treatment studies have addressed the topic of treatment of khat use disorders, all of whom used CBT techniques. A study in the north-west of Somalia (Somaliland) involving 35 patients compared a comprehensive treatment package for severe mental disorders with and without a psychoeducation component (psychoeducation included information on the negative effects of khat and on induced deterioration of psychotic symptoms, as well as advice and assistance to reduce use and it was addressed to patients and families). Both groups had reduced khat use in the early phase; however during the follow up most patients relapsed but those in the psychoeducation component group had a significantly lower frequency of use (30).

Concerning pharmacological treatment studies, nothing has ever been published except for some early case reports with bromocriptine (81), a substance that is not used any more for the treatment of addiction. Further research on pharmacological treatment is currently planned by the SARC initiative in Saudi Arabia.

\section{Rationale and evidence for prevention}

At present there is relatively little scientific knowledge on best practices, key concepts and evidence-based approaches available on khat-related preventive measures. Analysis of the 
current situation related to preventive measures demonstrates that national khat policies on prevention have rarely been implemented in khat-producing countries. The analysis of these national health-related strategies on khat is difficult because they have often not been sustained due to a lack of political will and because some of the countries are in transition and governance is constrained. Having analysed these attempts and reviewed previous writings by experts $(2,5,76)$, we propose the following five elements are needed in order to implement successful preventive measures.

1. Future measures should be strictly based on empirical evidence. Empirical research suggests that khat is a heterogeneous commodity and different use patterns exist.

2. The measures should be designed to be implemented in a sustained manner involving all stakeholders.

3. The target groups need to perceive preventive measures as neutral and health-related (e.g. reduce overuse and excesses, reduce agrochemical and toxin contamination or preserve traditional moderate khat use).

4. Future khat policies should use interstages between the extreme levels of the currently prevailing dichotomous approach (i.e. laissez-faire vs. legal ban, representing the extreme poles of the repertoire of possible actions) on khat and should include harm reduction and public health interventions. Measures should be multifaceted, adapted, differential and non-uniform.

5. Khat-related policies need to be coordinated and harmonized on a regional and international level.

We note that future research must test these guiding recommendations and improve on them to advance preventive interventions and achieve the desired outcomes.

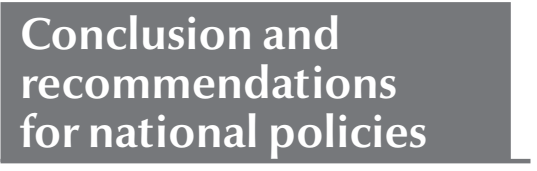

Given the complexity of the problem of khat use and its correlation with the cultural and societal structures of the consumers, WHO Member States have not yet adopted a systematic approach to address this growing problem. In order to gain a clear picture of the extent of the problem, a khatrelated data collection system needs to be integrated into the standard governmental statistical monitoring and reporting systems, e.g. in agriculture, trade, tax and health.

Data collection should be complemented by research on priority areas with the aim to better inform policy-makers and to empirically evaluate measures that have already been taken. Priority areas are:

- Develop and evaluate adequate research methods and resources for khat research (e.g. quick tests for khat alkaloids in body fluids).

- Determine the impact of khat use or overuse on the development of physical and mental health problems, e.g. schizophrenia, oral and gastric cancers or cerebral haemorrhage.

- Develop and evaluate effective interventions and methods of care for khat-related health problems.

- Develop and evaluate effective preventive measures.

In order to achieve these aims, research capacities need to be developed and research resources need to be made available in khat-use countries.

By including khat in consumer protection laws and related laws, minimum standards can be set to monitor and control khat production, distribution and consumption (e.g. define maximum permissible limits of relevant chemical compounds). At the same time, special prevention measures need to be taken to address vulnerable groups, including children and adolescents, people with pre-existing mental and physical disorders on whom khat has a proven negative effect, and women during pregnancy and breastfeeding and their children. General prevention measures need to be developed to inform the public about noxious khat use patterns (not of khat use per se), such as prolonged chewing or concomitant nicotine use, in order to clearly distinguish "traditional" khat use that probably causes little or no harm for healthy individuals from excessive use of khat.

For those who are affected by any kind of disorder related to khat use and comorbid conditions, treatment services should be provided. The focus is on primary health care where all patients should be routinely screened for substance use. At-risk substance users and concurrent users of khat and other substances, most notably nicotine, should be motivated to stop this practice, e.g. by applying the ASSIST-linked Brief Intervention for moderate khat users (82). The development of information material and manualized treatment tools for various severe user groups as well as the training of different specialists in the health care sector in order to detect and manage khat-related health problems are among the other basic measures that health systems can adopt. Appropriate specialized services are needed for treatment of khat dependency and also the comorbidity of khat use with mental disorders.

Funding: Michael Odenwald was supported by the German Federal Ministry of Education and Research grant number 01DG13020. Mustafa al'Absi and the KhatResearch Program (KRP) were supported by the Fogarty International Center grant (R03TW007219) and the National Institute on Drug Abuse under award number R21 DA024626. The content is solely the responsibility of the authors and does not necessarily represent the official views of the US National Institutes of Health.

Competing interests: None declared. 
1. Odenwald M, Klein A, Warfa N. Khat addiction. In: El-Guebaly N, Galanter M, Carrá G, editors. Textbook of addiction treatment: international perspective. New York: Springer; 2015.

2. Gatter P. Politics of Qat: the role of a drug in ruling Yemen. Wiesbaden: Ludwig Reichert Verlag; 2012:836p.

3. Griffiths P, Lopez D, Sedefov R, Gallegos A, Hughes B, Noor $\mathrm{A}$, et al. Khat use and monitoring drug use in Europe: the current situation and issues for the future. J Ethnopharmacol. 2010;132(3):578-83.

4. Al-Mugahed L. Khat chewing in Yemen: turning over a new leaf. Bull World Health Organ. 2008;86(10):741-2.

5. Odenwald M, Warfa N, Bhui K, Elbert T, et al. The stimulant khat-another door in the wall? A call for overcoming the barriers. J Ethnopharmacol. 2010;132(3):615-9.

6. Kalix P. Pharmacological properties of the stimulant khat. Pharmacol Ther. 1990;48(3):397-416.

7. Krikorian AD. Khat and its use: an historical perspective. In Shahandeh B, Geadah R, Tongue A, Tongue E, Rolli J, editors. The Health and Socio-Economic Aspects of Khat Use. International Conference on Khat, Antananarivo, Madagascar, January 17-21, 1983. Proceedings. Lausanne: International Council Against Alcohol and Addictions; 1983.

8. Carrier N, editor. Kenyan khat: the social life of a stimulant. Boston: Brill; 2007 [African Social Studies Series].

9. Widmann M, Warsame AH, Mikulica J, von Beust J, Isse MM, Ndetei D, et al. Khat use, PTSD and psychotic symptoms among Somali refugees in Nairobi -a pilot study. Front Public Health. 2014;2:71.

10. Al-Motarreb A, Baker K, Broadley KJ. Khat: pharmacological and medical aspects and its social use in Yemen. Phytother Res. 2002;16(5):403-13.

11. Hassan NA, Gunaid AA, El-Khally FM, Murray-Lyon IM. The effect of chewing Khat leaves on human mood. Saudi Med J. 2002;23(7):850-3.

12. Gebissa E. Keeping tradition and killing time: the use and misuse of khat in Ethiopia. In: Gebissa E, editor. Taking the place of food: khat in Ethiopia. Trenton (NJ): The Red Sea Press; 2010:57-88.

13. Negussie B. Substance use among high school students in Dire Dawa, Ethiopia. Harar Bulletin of Health Sciences. 2012;4(1):38-52.

14. Tulloch AD, Frayn E, Craig TK, Nicholson TR. Khat use among Somali mental health service users in South London. Soc Psychiatry Psychiatr Epidemiol. 2012;47(10):1649-56.

15. al'Absi M, Grabowski J. Concurrent use of tobacco and khat: added burden on chronic disease epidemic. Addiction. 2012;107(2):451-2.

16. Nakajima M, al'Absi M, Dokam A, Alsoofi M, Khalil NS, Al Habori $\mathrm{M}$. Gender differences in patterns and correlates of khat and tobacco use. Nicotine Tob Res. 2013;15(6):1130-5.

17. Kassim S, Islam S, Croucher RE. Correlates of nicotine dependence in UK resident Yemeni khat chewers: a cross-sectional study. Nicotine Tob Res. 2011;13(12):1240-9.

18. al'Absi M, Khalil NS, Al Habori M, Hoffman R, Fujiwara K, Wittmers L. Effects of chronic khat use on cardiovascular, adrenocortical, and psychological responses to stress in men and women. Am J Addict. 2013;22(2):99-107.

19. Hoffman R, al'Absi M. Working memory and speed of information processing in chronic khat users: preliminary findings. Eur Addict Res. 2013;19(1):1-6.
20. Nakajima M, Hoffman R, al'absi M. Poor working memory and reduced blood pressure levels in concurrent users of khat and tobacco. Nicotine Tob Res. 2013;16(3):279-87.

21. Nakajima M, Dokam A, Kasim AN, Alsoofi M, Khalil NS, al'Absi M. Habitual khat and concurrent khat and tobacco use are associated with subjective sleep quality. Prev Chronic Dis. 2014;11:E86

22. Banjaw MY, Schmidt WJ. Behavioural sensitisation following repeated intermittent oral administration of Catha edulis in rats. Behav Brain Res. 2005;156:181-9.

23. Milanovic B. Qat expenditures in Yemen and Djibouti: An empirical analysis. J Afr Econ. 2008;17(5):661-87.

24. Aden A, Dimba EA, Ndolo UM, Chindia ML. Socio-economic effects of khat chewing in north eastern Kenya. East Afr Med J. 2006;83(3):69-73.

25. Kassim S, Islam S, Croucher R. Validity and reliability of a severity of dependence scale for khat (SDS-khat). J Ethnopharmacol. 2010;132(3):570-7.

26. Nakajima M, Dokam A, Alsameai A, AlSoofi M, Khalil N, al'Absi $M$. Severity of khat dependence among adult khat chewers: the moderating influence of gender and age. J Ethnopharmacol. 2014;155(3):1467-72.

27. Kassim S, Hawash A, Johnston A, Croucher R. Validation of selfreported khat chewing amongst khat chewers: an exploratory study. J Ethnopharmacol. 2012;140(1):193-6.

28. Kassim S, Croucher R. Khat chewing amongst UK resident male Yemeni adults: an explanatory study. Int Dent J. 2006;56:97101.

29. Kassim S, Croucher R, Al'absi M. Khat dependence syndrome: a cross-sectional preliminary evaluation amongst UK-resident Yemeni khat chewers. J Ethnopharmacol. 2013;146(3):835-41.

30. Odenwald M, Lingenfelder B, Peschel W, Haibe FA, Warsame AM, Omer A, et al. A pilot study on community-based outpatient treatment for patients with chronic psychotic disorders in Somalia: Change in symptoms, functioning and co-morbid khat use. Int J Ment Health Syst. 2012;6(1):8.

31. Awas M, Kebede D, Alem A. Major mental disorders in Butajira, southern Ethiopia. Acta Psychiatr Scand Suppl. 1999;397:5664.

32. Bongard S, Nakajima M, al'Absi M. Khat chewing and acculturation in East-African migrants living in Frankfurt am Main/ Germany. J Ethnopharmacol. 2015;164:223-8.

33. Bhui K, Craig T, Mohamud S, Warfa N, Stansfeld SA, Thornicroft $\mathrm{G}$, et al. Mental disorders among Somali refugees. Developing culturally appropriate measures and assessing socio-cultural risk factors. Soc Psychiatry Psychiatr Epidemiol. 2006;41:400-8.

34. Odenwald M, Hinkel H, Schauer E, Schauer M, Elbert T, Neuner $\mathrm{F}$, et al. Use of khat and posttraumatic stress disorder as risk factors for psychotic symptoms: a study of Somali combatants. Soc Sci Med. 2009;69(7):1040-8.

35. Odenwald $M$, Lingenfelder B, Schauer M, Neuner F, Rockstroh B, Hinkel H. Screening for posttraumatic stress disorder among Somali ex-combatants: a validation study. Confl Health. 2007;1:10.

36. Teferra S, Hanlon C, Alem A, Jacobsson L, Shibre T. Khat chewing in persons with severe mental illness in Ethiopia: a qualitative study exploring perspectives of patients and caregivers. Transcult Psychiatry. 2011;48(4):455-72.

37. Odenwald M. Chronic khat use and psychotic disorders: a review of the literature and future prospects. Sucht. 2007;53(1):922. 
38. Bimerew MS, Sonn FCT, Korlenbout WP. Substance abuse and the risk of readmission of people with schizophrenia at Ammanual Psychiatric Hospital, Ethiopia. Curationis. 2007;30(2):74-81.

39. Odenwald M, Neuner F, Schauer M, Elbert T, Catani C, Lingenfelder B. Khat use as risk factor for psychotic disorders: A cross-sectional and case-control study in Somalia. BMC Med. 2005;3(1):5.

40. Kroll J, Yusuf AI, Fujiwara K. Psychoses, PTSD, and depression in Somali refugees in Minnesota. Soc Psychiatry Psychiatr Epidemiol. 2010;46:481-93.

41. Bhui K, Warfa N. Trauma, khat and common psychotic symptoms among Somali immigrants: A quantitative study. J Ethnopharmacol. 2010;132(3):549-53.

42. Al-Motarreb A, Al-Habori M, Broadley KJ. Khat chewing, cardiovascular diseases and other internal medical problems: The current situation and directions for future research. J Ethnopharmacol. 2010;132(3):540-8.

43. Al-Habori M. The potential adverse effects of habitual use of Catha edulis (khat). Expert Opin Drug Saf. 2005;4(6):1145-54.

44. Date J, Tanida N, Hobara T. Qat chewing and pesticides: a study of adverse health effects in people of the mountainous areas of Yemen. Int J Environ Health Res. 2004;14(6):405-14.

45. Daba D, Hymete A, Bekhit AA, Mohamed AM, Bekhit Ael-D Multi residue analysis of pesticides in wheat and khat collected from different regions of Ethiopia. Bull Environ Contam Toxicol. 2011;86(3):336-41.

46. Halboub E, Dhaifullah E, Abdulhuq M. Khat chewing and smoking effect on oral mucosa: a clinical study. Acta Med (Hradec Kralove). 2009;52(4):155-8.

47. Lukandu OM, Koech LS, Kiarie PN. Oral lesions induced by chronic khat use consist essentially of thickened hyperkeratinized epithelium. Int J Dent. 2015;2015:104812.

48. Getahun W, Gedif T, Tesfaye F. Regular khat (Catha edulis) chewing is associated with elevated diastolic blood pressure among adults in Butajira, Ethiopia: a comparative study. BMC Public Health. 2010;10:390.

49. Al Suwaidi J, Ali WM, Aleryani SL. Cardiovascular complications of Khat. Clin Chim Acta. 2013;419:11-4

50. Vanwalleghem IE, Vanwalleghem PW, De Bleecker JL. Khat chewing can cause stroke. Cerebrovasc Dis. 2006;22(2-3):198200 .

51. Mohammed A, Engidawork E. Reproductive parameters are differentially altered following subchronic administration of Catha edulis Forsk (Khat, Celastraceae) extract and cathinone in male rats. J Ethnopharmacol. 2011;134(3):977-83

52. Chapman $\mathrm{MH}$, Kajihara M, Borges G, O'Beirne J, Patch D, Dhillon AP, et al. Severe, acute liver injury and khat leaves. $N$ Engl J Med. 2010;362(17):1642-4.

53. Mwenda JM, Arimi MM, Kyama MC, Langat DK. Effects of khat (Catha edulis) consumption on reproductive functions: a review. East Afr Med J. 2003;80(6):318-23.

54. Nyongesa AW, Oduma JA, Nakajima M, Odongo HO, Adoyo PA, al'Absi M. Acute and sub-chronic effects of purified cathinone from khat (Catha edulis) on behavioural profiles in vervet monkeys (Chlorocebus aethiops). Metab Brain Dis. 2013;29(2):441-9.

55. Nyongesa AW, Oduma JA, Nakajima M, Odongo HO, Adoyo PA, al'Absi M. Dose-response inhibitory effects of purified cathinone from khat (Catha edulis) on cortisol and prolactin release in vervet monkeys (Chlorocebus aethiops). Metab Brain Dis. 2013;29(2):451-8.

56. Colzato LS, Ruiz MJ, van den Wildenberg WP, Hommel B. Khat use is associated with impaired working memory and cognitive flexibility. PLoS One. 2011;6(6):e20602
57. Hoffman R, Al'Absi M. Khat use and neurobehavioral functions: suggestions for future studies. J Ethnopharmacol. 2010; 132(3):554-63.

58. Hoffman $\mathrm{R}, \mathrm{Al}^{\prime}$ absi M. Concurrent use of khat and tobacco is associated with verbal learning and delayed recall deficits. Addiction. 2013;108(10):1855-62.

59. Bongard S, al'Absi M, Khalil NS, Al Habori M. Khat use and trait anger: effects on affect regulation during an acute stressful challenge. Eur Addict Res. 2011;17(6):285-91.

60. Nakajima M, al'Absi M. Psychosocial deterrents of tobacco and khat use among men and women. Public Health. 2013;127(7):684-6

61. al'Absi M, Nakajima M, Dokam A, Sameai A, Alsoofi M, Saem Khalil N. Concurrent tobacco and khat use is associated with blunted cardiovascular stress response and enhanced negative mood: a cross-sectional investigation. Hum Psychopharmacol. 2014;29(4):307-15

62. Global Health Risks: Mortality and burden of disease attributable to selected major risks. Geneva: World Health Organization; 2009.

63. Al-Sanosy RM, Mahfouz MS, Gaffar AM. Khat chewing habit among school students of Jazan region, Saudi Arabia. PLoS One. 2013;8(6):e65504.

64. Al-Sanosy RM. Pattern of khat abuse and academic performance among secondary school and college students in Jazan region, Kingdom of Saudi Arabia (KSA). J Family Community Med. 2009;16(3):89-95.

65. Sheikh KA, El-Setouhy M, Yagoub U, Alsanosy R, Ahmed Z. Khat chewing and health related quality of life: cross-sectional study in Jazan region, Kingdom of Saudi Arabia. Health Qual Life Outcomes. 2014;12:44.

66. Alsanosy RM, Mahfouz MS, Gaffar AM. Khat chewing among students of higher education in Jazan region, Saudi Arabia: prevalence, pattern, and related factors. BioMed Res Int. 2013;2013:487232.

67. Mahfouz MS, Alsanosy RM, Gaffar AM. The role of family background on adolescent khat chewing behavior in Jazan Region. Ann Gen Psychiatry. 2013;12(1):16.

68. Alsanusy R, El-Setouhy M. Why would khat chewers quit? An in-depth, qualitative study on Saudi Khat quitters. Subst Abus. 2013;34(4):389-95.

69. Abednego M, Veltrup C, Warsame AH, Isse MM, Widmann M, Ndetei D, et al. Developing an integrated treatment for PTSD and khat dependence: results from a case series among Somali refugees. Paper presented at the XIV Conference of European Society for Traumatic Stress Studies, 10-13 June 2015, Vilnius, Lithuania.

70. Widmann M, Veltrup C, Apondi B, Warsame AH, Abednego M, Ndetei $D$, et al. Brief intervention to reduce khat consumption: Do clients with PTSD show smaller effects? Paper presented at the XIV Conference of European Society for Traumatic Stress Studies, 10-13 June 2015, Vilnius, Lithuania.

71. Odenwald M, Hinkel H, Schauer E, Neuner F, Schauer M, Rockstroh B, et al. The effect of khat on psychotic disorders: the validation of a measurement method for clinical practice in Somalia. Poster presented at the CPDD 70th Annual Scientific Meeting, San Juan, Puerto Rico, 14-19 June, 2008.

72. WHO Expert Committee on Drug Dependence. Thirty-fourth report. Geneva: World Health Organization; 2006:36 (Technical Report Series No. 942).

73. van Amsterdam J, Opperhuizen A, Koeter M, van den Brink W. Ranking the harm of alcohol, tobacco and illicit drugs for the individual and the population. Eur Addict Res. 2010;16(4):202-7. 
74. Nutt DJ, King LA, Phillips LD; Independent Scientific Committee on Drugs. Drug harms in the UK: a multicriteria decision analysis. Lancet. 2010;376(9752):1558-65.

75. Report of the Sixth Meeting of the Regional Advisory Panel on Impact of Drug Abuse (RAPID 6), Cairo, Egypt, 16-19 October 2007. Cairo: World Health Organization Regional Office for the Eastern Mediterranean; 2008:16 (Key messages on khat) (http://apps.who.int/iris/bitstream/10665/115923/1/who_ em_mnh_181_e_en.pdf, accessed 13 December 2016).

76. EMCDDA. Khat use in Europe: implications for European policies. Drugs in Focus - Briefing of the European Monitoring Centre for Drugs and Drugs Addiction. Lisbon: European Monitoring Centre for Drugs and Drugs Addiction; 2011.

77. Odenwald M, Hinkel H, Schauer E, Neuner F, Schauer M, Elbert TR, et al. The consumption of khat and other drugs in Somali combatants: a cross-sectional study. PLoS Med. 2007;4(12):e341.
78. Kraagegaard I. Linking social work and treatment efforts in connection with khat addiction in diaspora. Paper presented at the ESF-LiU conference "The changing use and misuse of Catha edulis (khat) in a changing world: tradition, trade and tragedy". Linköping, Sweden, 5-9 October 2009.

79. Al-Khalil IB. Aarhus reaches out to khat addicts. Aarhus, Denmark: Aarhus Municipality; 2010:12.

80. Abdi YA. Khat -en tuggande bomb [Khat - a chewing bomb]. Stockholm: Vardguiden; 2012:10-1.

81. Giannini AJ, Miller NS, Turner CE. Treatment of khat addiction. J Subst Abuse Treat. 1992;9(4):379-82.

82. Humeniuk R, Henry-Edwards S, Ali R, Poznyak V, Monteiro M. The ASSIST-linked brief intervention for hazardous and harmful substance use: manual for use in primary care. Geneva: World Health Organization; 2010. 